\title{
Comparative Study of Sino-Russian Modern Wind Music Teaching
}

\author{
Fei Wang \\ School of Music \\ Heihe University \\ Heihe, Heilongjiang, China 164300
}

\begin{abstract}
Russian national music and Chinese national music are respective traditional musical culture form, both of which embody the law of music development in common during their development and evolution, meanwhile however, reflect the musical connotation and technique of expression peculiar to the two different cultures. In this article, it analyzes the differences and similarities between the two musical form from the aspects of the differences and similarities of the development of wind music teaching between China and Russia emphatically.
\end{abstract}

Keywords-modern wind music; Russian national music; Chinese national music

\section{INTRODUCTION}

Wind music is of long standing indeed as one of music class. In music culture, it exists for a reason that as the important part of musical art, wind music is not only with the characteristics of beauty of timbre and harmony, but also contains abundant aesthetic consciousness and is the significant carrier of aesthetic education. And there are many differences between China and Russia concerning modern wind music teaching.

\section{The CuRRent Situation of Wind Music Teaching IN DOMESTIC COLLEGES}

At present, the musical art course in domestic colleges has improved and developed in a great degree, particularly the wind music course has developed rapidly. More and more students of music major start to learn the performance methods of wind instruments on purpose, or choose one kind of wind instruments as their own minor subject in college. In addition, there are amounts of musical basic theoretical knowledge included in wind music study, which can promote the students' basic skills and musical professionalism, hence, the wind instrument has become the first choice for the students gradually. However, through wind music education has seen a rapid development in colleges these years, there are still many defects existing in domestic wind music education. As a rule, the students are prone to feel bored while in learning process; meanwhile, it is a great challenge for the students to persist in practice; for another, due to differences between different cities in economic development, the colleges pay attention to the art of wind music in different degrees. Moreover, learning wind music course also requires profound music foundation while due to the imperfect development of quality education of elementary and secondary school in our country as well as the students pay less attention on music course, which results in the college students have limited ability to learn wind music instrument as well.

\section{THE DIFFERENCES OF MODERN WIND MUSIC TEACHING BETWEEN CHINA AND RUSSIA}

\section{A. Major Setup}

In Russia, the music education programs in college have been divided into piano, orchestral music, folk music, chorus conducting, vocal music, theory, secondary school teacher diploma and other major orientations at the beginning of enrollment interview. The national teaching program of Russian institutions of higher learning states that: major orientation is a part of major learning, which means to acquire deeper professional knowledge and technique in some field of the major. Through domestic music education programs in college have major elective courses as well in senior grades, the major orientation setup as well as the major course setup after enrollment of Russian music education programs in college are more like the domestic performance major or school of music, taking piano as instance, the provided exam chapters are: 1. Bach polyphonic works, 2. Two movements of classical sonata (movement I or II and movement III) 3, Opusculum (recital works) 4, etudes, which reflect that the Russian music education programs in college have a strong major tendency all along.

While in normal colleges of China, they adopt teaching model of 1 to 1 or 1 to two, which have respective characteristics: for " 1 to 1 ", it can almost solve problems on purposes completely, teach students in accordance of their aptitude and be flexible and free on teaching schedule; for " 1 to 2", the best advantage is that the students can promote learning and progress mutually as well as with respect to duet practice, the teaching model of " 1 to 2 " is more rational.

\section{THE DIFFERENCES OF MAJOR EXAMINATION CONTENTS}

The writer investigates the examination auxiliary class of Moscow National Normal University, so that has a relatively comprehensive understanding of part students' professional level. Taken piano as instance, as I know most examinees play Bach by equal temperament and there are English Suites and Italian concerto as well. Provided that only from the view of the examinees, most students have been relatively standard, not only the musical structure but also the vertical and lateral 
control of timbre and voice part. Overall, the examinees' performance ability is above ours multi-dimensionally, more or less between domestic normal university and school of music. It is observed that the piano performance art training they undergone and understanding to which are more standard and comprehensive than us. While review the examinees of normal universities of our country, the music education they undergone is family education model, lacking of professional practice, particularly systemic professional theory study. Even raid-type learning music several months before the examination is very common. Due to the fact that large amounts of students we recruit while the examination time of instrumental music and vocal music is controlled in 3-5 minutes in normal, which has formed into tradition, objectively resulting in the unusual phenomena of promoting degree of musical selection as well as selecting paragraph randomly. Scientific and reasonable planning the music education system in the universities of our country has been an urgent affair.

\section{THE PREDOMINANT DIRECTION OF RUSSIAN MODERN WIND MUSIC}

In modern world, the performance and teaching level of Russian brasses lies in the top position all the time. During the writers' school life in Russia, it is found that, comparing with some domestic teaching methods, the Russian has some differences on emphasis and is more comprehensive on involved content and with relatively novel views.

\section{A. Russian Trumpet Attaches Importance to Tonguing Technique and Tongue Training}

The starting moment in trumpet pronunciation is called as "starting voice", which demands that the tongue tip passes through the gap between upper incisor and lower incisor, lightly contacting the edge of internal upper lip, meanwhile the tongue tip should feel the upper incisor, then the tongue tip instantly "hides" in the back of lower incisor and guides the next tonguing. The tonguing technique of tongue composes of the following aspects: 1 . the tongue tip should be in the teeth root of internal upper incisor; 2 . once the breath flows upon mouth cavity, the tongue should fall down rapidly, meanwhile contain a stream of air flow in pronunciation of "Ta" or other syllables imaged by the performer. Pronounce "Ta" in bass area, "Tu" in median area while "Ti" in treble area. In bass area, bend downwards tongue to make it be in the middleupper part of the mouth cavity, like an upside down bowl. When perform the bass area, the mouth cavity should open to the biggest like yawn (the lip shape should not change) while for treble area, the mouth cavity should change to rather small. Secondary, it should be stressed that if sound head control is required while correct and coordinated breath is required, also the lip and muscles around the cheek should be in relative relax status, so that the performer will have chance and strength to play techniques by utilizing lips and tongue.

\section{B. Application and Maintenance of Respiration When Performs}

The performer's respiratory techniques should be taken into consideration before learning all the techniques. Sound techniques include various conducts of timbre and melody, specific characteristics of sound and lips, the vocal organ. The trumpeter's professional respiration - which refers to the process that control all the muscles used in respiration on purpose, so as to perform breath characteristics required by different sounds and effects. However, this control consciousness should be established as the top status in all the performance techniques.

In actual performance, the most reasonable respiration for trumpeter should be active control of the muscles and thoracic diaphragm in external intercostals. Before performance, the trumpeter should breathe briefly, sufficiently and soundlessly. When take a breath, the breath should pass through corners of lips rapidly meanwhile the mouth mustn't separate from lips. When exhaling, the breath should be quick, soundless and flexible while it passes through the mouth cavity and fill up the whole mouth cavity. That means to ensure the breath's "flow velocity" and its "flow quantity" as well. The trumpeter should pay more attention to keep this status no matter any sound or music in any range or speed you performed.

The correct way to breathe should always keep the breath capacity of the starting voice (except when there are special requirements in the music). And the sudden enhancing or diminishing of breath capacity should be avoided, that is, keeping the sound stability whose impetus is due to the pressure from abdominal muscle. During the teaching process, the teacher could recommend students to do separate breathing exercises without instruments so as to enhance the breath capacity of students. There are many ways of this kind of exercises aiming to enhance the breath capacity and the control of breath of the trumpeters. Finally, it should be noted that for the purpose of enhancing the breath capacity and achieving the requirements of professional performers, they must do physical exercises regularly and intensify the training of prolonged sound, the Cantata style of tanka and other types of music.

\section{THE INFLUENCE OF RUSSIAN WIND MUSIC ON THE REFORM OF WIND MUSIC IN DOMESTIC COLLEGES}

\section{A. Enhancing the Basic Skill Training}

None of the wind music performers could succeed without the usual hard training. This is especially true to the college students whose basic skills are relatively weak, so they should put more attention on the basic skill training. The basic training of wind music arts includes respiration training and syllable training. Just like the performing of string music can't be done without bows, the performing of wind music can't be done without respiration. During the process of wind music performing, the respiration of the performer has the direct influence on the veracity and the beauty degree of sound quality. Respiratory techniques are mainly divided into thoracic-abdominal respiration and abdominal respiration which decide the tone, diapason and tune quality of the musicians' outputs during the process of playing the instruments. During the performance of wind music, the art of playing possesses highly skillful respiration which is achieved by the constantly postnatal hard training. In addition, while emphasizing on the technical training, the wind music teachers should strengthen the teaching of wind music background and the interpretation of styles to improve the comprehensive 
ability of students so that they can continually improve the comprehensive ability and performance ability during the understanding and performing process.

\section{B. Enhancing The Study of Related Knowledge}

Music compositions are rather the products of an era than the intellectual products. The comprehensive culture of social phenomenon, politics and economy etc of each period forms various musical phenomenon. Therefore, during the teaching process, the college music teachers should lead students to know and learn the humanistic knowledge of related disciplines such as history, religion and sociology and so on.

\section{Enhancing the Education of Practical Training}

For the training of innovation ability and spirit of students, colleges should pay attention to the artistic practice link and give students more opportunities to perform and practice so that students can truly master the art and skill of wind music. At present, during the teaching of wind music art in colleges, most wind instruments that teachers adopt include saxophone, trumpet, trombone, clarinet and flute etc. However, just practicing and performing in front of teachers and students in school is different from the real stage. Overseas, many conservatories focus more on the practice and practical performance of students and provide students with abundant wind music training stages like small school concerts and wind symphony orchestras and so on. During the constantly participating of real performing process, students can find their limitations as well as demonstrate their advantages and promote their professional technical capability. As a result, the civil colleges should learn from those schools and provide students with more opportunities for practical training.

\section{Using Positive Evaluation to Enhance Communication}

The evaluation from the teachers plays a certain catalytic role in the improvement of students and is also the impetus to the studying of them. Teachers could set up the Expert Instruction Classes so that the students can participate in the analysis of others' performance and share their own understanding as well as receive the evaluation from experts and others, at the same time, master the quintessence of wind music during the communicating process and try harder to do better. As the old saying goes, "There must be one out of three who can be your teacher", teachers should provide more opportunities for students to exchange and organize various kinds of professional exchange activities so that they can learn the advantages of others and improve their own shortcomings in the communication and exchange with professional students. Besides, teachers could use the modern teaching method of popular multimedia to let the students listen more and see more and receive the artistic influence so as to train the ability of art appreciation of students.

\section{E. The Launching of Wind Music Rehearsal}

Wind music rehearsal is an important course which can improve the understanding of music works and cooperation among each other. However, many schools haven't taken much care of the music rehearsal, causing that the performance ability of students can't be improved. The main content of music rehearsal is that students can master the basic knowledge of music and possess the thorough performance skills and the ability of performing with others. Meanwhile, teachers play an important role in the wind music rehearsal. They must has relatively abundant performing skills and theoretical knowledge and know about the basic performance methods of every instrument and they'd better be proficient in several kinds of instruments, showing performance demonstration if necessary. Usually, at the beginning of wind instruments courses, students are not capable of performing correct and right sounds, on the country, they are more likely to perform strange and incorrect sounds. Here, teachers should guide with patience and teach one by one from the mouth shape, posture to the handle of respiration till students can perform the right sounds. The guide teachers must not be impatient and has a rush for quick results, whereas, they should give students time to learn and adapt. The teaching tasks for teachers are relatively heavy because they need to train students the ability to master various kinds of instruments one after another.

\section{CONCLUSION}

In a word, the education of the art of wind music in domestic colleges is an important component of the aesthetic education and humanistic quality education, the status of which in the cultivation of comprehensive quality of students is unallowable to be neglected. Therefore, if the teaching of wind music in the college music education wants to adapt to the demands for talents in new period, it must be reformed in the management system and the use of Russian excellent teaching resources so that students can master professional skills through constantly performing and practice. Only in this way can the full-scale and super strong and comprehensive cultural quality be cultivated.

\section{REFERENCES}

[1] Shaolu \& Philharmonic. Russian Miracle-Mousso Ugorski Orchestral Works, July 10th, 2009, Magazine.

[2] Li Ke \& Huang Zhong. Thinking from St Petersburg, Research on the Teaching System of St Petersburg State-Maintained Rimsky-Korsakov Conservatory of Music, Wuhan, China Conservatory of Music Journal), Jan. 25th 2014, Magazine. 